\title{
How organisations can affect employees' intention to manage enterprise-specific knowledge through informal mentoring: a vignette study
}

\author{
Conny J.J. Roobol and Ferry Koster
}

\begin{abstract}
Purpose - The purpose of this study is to examine the role of organisational conditions and workplace characteristics in midcareer and senior employees' intention to volitionally provide career support to junior organisational members, their protégés.

Design/methodology/approach - Hypotheses are tested using multilevel linear modelling on a heterogeneous sample of Dutch employees ages 29 to 69 who participated in a vignette study in the autumn of 2017.

Findings - In line with the hypotheses, the findings of this study show that volitional (informal) mentoring is positively related to an organisation's endorsement of intrinsic values (e.g. learning opportunities) and negatively to the presence of hindrance demands (e.g. time pressure).

Practical implications - Practitioners could facilitate co-mentor consultation, employ autonomysupportive direct supervisors and fulfil psychological contract obligations by providing job security and learning opportunities. Organisations could also lower time pressures through job carving.

Originality/value - This study extends extant mentoring research by combining insights from perceived organisational support (POS) and self-determination theory (SDT) to examine the role organisational conditions and workplace characteristics play in aiding or hindering volitional mentoring. It enriches extant knowledge management studies on the link between organisational aspects and (intended) knowledge sharing behaviour by showing that similar organisational motivators predict volitional mentoring, thereby launching a call to study knowledge management through volitional mentoring using a SDT- and POS-based lens. A methodological novelty is the reliance on a vignette study.
\end{abstract}

Keywords Mentoring, Self-determination theory, Perceived organisational support, Vignettes, Knowledge management

Paper type Research paper

\section{Introduction}

Mentoring is regarded as one of the major ways in which organisations can manage their knowledge. As Wickert and Herschel (2001) state, knowledge management (KM) depends upon human interaction. Creating mentoring relations can be an effective means to establish such interaction (Wickert and Herschel, 2001), which ultimately contributes to the extent to which knowledge is shared in organisations (Karkoulian et al., 2008; Nguyen et al., 2019). More formally, mentoring (along) with training is viewed as one of the core practices of an organisation's KM system (Gallupe, 2001). Through the transfer of career- or jobrelated knowledge from midcareer and senior employees or mentors to junior organisational members or protégés, organisations archive craftsmen knowledge about previously solved issues. As such, mentoring prevents organisations from reinventing the wheel.
Conny J.J. Roobol and

Ferry Koster are both based at the Department of Public

Administration and

Sociology, Erasmus

University Rotterdam,

Rotterdam, The Netherlands.

Received 3 November 2018

Revised 13 July 2019

25 January 2020

25 May 2020

Accepted 29 May 2020

(C) Conny J.J. Roobol and Ferry Koster.Published by Emerald

Publishing Limited. This article is published under the Creative

Commons Attribution (CC BY 4.0)

licence. Anyone may reproduce, distribute, translate and create derivative works of this article (for both commercial and noncommercial purposes), subject to full attribution to the original publication and authors. The full terms of this licence may be seen at http://creativecommons.org/licences/ by/4.0/legalcode

This work was financially supported by the Netherlands Organization for Scientific Research, TOP Grant "Sustaining Employability" (NWO 407-13-021). This financial sponsor has approved of the research question that informs the PhD project of the first author's dissertation. No active involvement could be reported in the design of this particular manuscript. Disclosure of interest. The authors report no conflict of interest. Data availability statement. The data that support the findings in this study are not yet stored in a public repository. The authors are, however, willing to share (parts of) the data upon a reasonable request for disclosure. 
Despite mentoring being a means to manage enterprise-specific knowledge, studies have predominantly focussed on the protégé (Allen, 2007). As far as the mentor has been the focus of scholarly inquiry, research has examined how individual-level aspects, such as dispositional variables, affect employees' willingness to become a mentor (Allen, 2003, 2007). However, the literature is largely missing an examination of the role of contextual aspects in the intention to mentor, such as organisational conditions (e.g. Human Resource (HR) policies) or workplace characteristics. This lacuna is remarkable, given the embeddedness of mentorships in organisations (Allen, 2007) and the presumed benefits of mentoring for this aggregate (e.g. knowledge preservation). Our research question, therefore, is:

$R Q 1$. Under which organisational conditions and workplace characteristics are midcareer and senior (experienced) employees most willing to provide career support to junior organisational members?

Our search to answer this question extends extant mentoring and KM research in three ways. First, whilst Kram (1985) argued that organisations could affect mentorships, only two empirical studies (Allen et al., 1997a; Billett, 2003) have examined the role of organisational conditions in (experienced) employees' willingness and capacity to mentor others. Both studies are qualitative in nature, and although descriptions are rich, the foundations for causality are poorly laid. By conducting a quantitative study, we aim to examine in a systematic way the role of organisational conditions and workplace characteristics in the general willingness to mentor.

Second, despite recommendations for a (semi-)experimental design (Allen et al., 2008), few mentoring studies have relied upon this model. We respond to this call by conducting a vignette study. A vignette study or factorial survey is a semi-experiment in which respondents base their social judgements (e.g. estimations of their mentoring intentions) on an experimentally manipulated set of hypothetical yet realistic principles (e.g. organisational conditions; Rossi and Anderson, 1982). A vignette study is useful for four reasons. First, vignettes borrow the idea of factor orthogonality from factorial experiments in which principles are uncorrelated (Rossi and Anderson, 1982). This perfect non-association enables us to study the unbiased effect of workplace conditions on respondents' mentoring intentions. Second, respondents' unawareness of the factor manipulation enables us to minimise social desirability that would otherwise result from public attention to workplace learning. Because of this advantage, a vignette study is also well-suited to address a socalled "cooperation bias" - a validity threat that results from an overrepresentation of those who are cooperative relative to survey requests (Witherspoon et al., 2013). Such a bias often plagues studies on knowledge sharing (KS) intentions, as those who are cooperative are also those who provide a desirable answer, that is, who overestimate their intentions to act. Third, vignettes enable us to study the actual antecedents of mentoring intentions because we can confront respondents with conditions of which they might be unaware but cannot ignore whilst providing their judgements (Wallander, 2009). Fourth, by confronting respondents with a sample of principles (instead of the full set), multiple sets of principles can be discerned (Rossi and Anderson, 1982). This feature of traditional surveys enables us to model multiple combinations of workplace conditions, thereby ensuring greater resemblance between experimental and real-life work situations.

Third, we combine insights from perceived organisational support (POS) and selfdetermination theory (SDT) to develop an integrated model of the intention of midcareer and senior employees to become mentors. A point of departure is that mentoring constitutes a pro-organisational activity through its successorship of enterprise-specific knowledge. Such an integrated model lays the foundation for future theory on mentoring relationships from the mentor's perspective. This model extends our knowledge, as studies that have relied on POS or SDT have investigated only the protégé's perspective (Baranik et al., 2010; Baranik et al., 2017; Park et al., 2016; an exception being Janssen et al., 2014). 
We collected data in the Netherlands, a country where the labour force is rapidly ageing (CBS, 2018) and issues regarding sustainable employment dominate public debates. Participation in formal training activities decreases with age, while involvement in informal activities does not (Pleijers and De Winden, 2014). Against this background, it is interesting to study how experienced employees' engagement in informal learning practices - such as mentoring - could be stimulated to uphold a skilled labour force.

\section{Mentoring: a definition}

The motivation to mentor depends on the type of mentorship under consideration (Allen, 2003); therefore, we must explain what the term "mentoring" means. In this study, we focus on informal mentoring aimed at career support or "a spontaneously developed and informal form of providing career support that is not officially mandated within the organisation and characterised by an often intimate, interpersonal relation between the mentor and the protégé as well as by informal rules regarding contract duration, targeted goals and interaction frequency and content" (Allen, 2003, p. 136; Eby and Lockwood, 2005, p. 442). A first feature of mentoring is the provision of career support, which means that the mentor transmits job-related knowledge to the protégé and assists the individual's career advancement. Doing so empowers the protégé and, thus, helps organisations manage enterprise-specific knowledge. A second feature of mentoring is that mentorships are not formally arranged and, hence, not structured along stringent (selection) criteria and tight guidelines (Allen, 2003). Therefore, we focus on informal mentorships that are governed by reciprocity rules of exchange (parties abide by unspecified and unwritten obligations and rights that are usually not subjected to a formal bargaining process; Cropanzano and Mitchell, 2005). A final, inherent feature of these so-called "informal mentorships" is that they develop naturally (Ragins and Scandura, 1999) without an internal mandate, meaning that mentoring has a volitional nature and is often not an integral part of employees' formal job description and remuneration. Together, these features enable us to study informal mentorships through the lens of organisational citizenship behaviour (OCB) or "employee behaviour that is discretionary (i.e. not an essential part of one's contractual tasks, also called extra-role behaviour), not formally rewarded, and [supposed to] benefit the functioning of the organisation" (Organ, 1988, p. 4).

This link follows Allen's $(2003,2007)$ suggestion to define mentorships as a particular dimension of OCB. Her reasoning is based on the result that dispositional aspects generally found to affect pro-social behaviour (outside of work) appear also to relate to employees' propensity to become mentors (Allen, 2003). Recent research (Janssen et al., 2014) strengthened Allen's $(2003,2007)$ presupposition by showing that motivations to mentor not only are limited to the perceived personal benefits but also are relational, with mentors showing concern for their protégés or their organisations. In sum, acknowledging that informal mentoring is a form of OCB that can be relational in nature is crucial to our understanding of the role that organisational conditions and workplace characteristics which we refer to as the "work environment" below - play in incentivising midcareer and senior employees to become informal mentors.

\section{A self-determination theory- and perceived organisational support-based approach to mentoring}

A thorough review of the literature on the mentor's perspective on mentoring revealed five core organisational determinants for general willingness to mentor: co-mentor consultation, supervisory support for (volitional) mentoring, learning opportunities, time pressure and organisational restructuring (an overview is available upon request). In this study, we rely on a combined SDT and POS theoretical perspective to detail the mechanisms linking these determinants to midcareer and senior employees' intention to volitionally mentor protégés. The theoretical point of departure is that volitional mentoring constitutes an exemplary form 
of optimal worker functioning. According to SDT, optimal functioning or "[...] employees' [positive] attitudes towards the organisation" (Van den Broeck et al., 2014, p. 1907) is instigated by a theoretical mechanism called basic need fulfilment, especially when activities are undertaken volitionally (Gagné and Deci, 2005). Employees need to feel part of a community (need for relatedness), to be enabled to work in a self-directed manner (need for autonomy) and to feel capable of doing their work (need for competence). These needs are posited to be fulfilled through a social context that promotes values such as affiliation, personal growth, empowerment and community contribution (Gagné and Deci, 2005; Van den Broeck et al., 2014). Detailing these so-called "intrinsic values" (Van den Broeck et al., 2014) is central to SDT's qualitative approach to values that pays attention to the content rather than the amount of value endorsement necessary for optimal functioning.

Decades of research in domains such as sports, education and parenting have shown that intrinsic value endorsement facilitates individuals' adaptive behaviours, optimal functioning and performance (Gagné and Deci, 2005). Although relatively scarce, studies that test SDTbased premises in organisational settings revealed similar findings: through intrinsic value endorsement, organisations receive a benefit in the form of worker solidarity, optimal functioning and performance (Gagné and Deci, 2005; Van den Broeck et al., 2014).

While the former paragraphs portray intrinsic value endorsement objectively, it is widely believed that employees' actions emanate from their perceptions of the (work) environment rather than from any objective situation (Van Emmerik et al., 2012). Employees' perceptions of their organisations' intrinsic values are often subsumed under the term perceived organisational support or POS. POS is commonly defined as employees' perceptions about the extent to which their organisations appreciate their contributions and show genuine interest in their well-being and development (Eisenberger et al., 1986; Koster et al., 2011).

Recently, POS has been studied in relation to SDT, with Gagné et al. (2010) showing that POS positively relates to Canadian airline workers' autonomous (volitional) motivation. Adding to this, Gillet et al. (2013) evinced that POS was positively associated with French police officers' autonomous (volitional) motivation and effective organisational orientations. In both studies, POS was used to denote the organisational values needed to elicit optimal worker functioning. As we conceptualise mentoring as a form of optimal worker functioning, we assert that POS can also be considered a useful umbrella concept for the intrinsic value support that midcareer and senior employees experience in their work environments. In announcing this contention, we assume that intrinsic value support forms a powerful predictor of volitional mentoring, following numerous previous studies on the central role POS plays in boosting optimal (worker) functioning and OCB (Cropanzano and Mitchell, 2005).

In addition to organisational conditions that fulfil employees' basic human needs, some aspects of the work environment may thwart basic human need fulfilment. In studies on organisational theories (Van den Broeck et al., 2010), these workplace characteristics are coined hindrance demands. Typical hindrance demands are role conflict, role ambiguity, job insecurity and also, when individual appraisals are taken into consideration, time pressure (e.g. workload; Van den Broeck et al., 2010; Webster et al., 2011). A built-in feature of hindrance demands is that they tax individuals' energy reservoirs and, as need barriers, can be expected to lower optimal functioning (Van den Broeck et al., 2010). Research has provided support for this premise, showing that hindrance demands or appraisals are detrimental to employees' health, well-being, job satisfaction and organisational commitment (Webster et al., 2011).

\section{Hypotheses}

Analogous to a SDT and POS theoretical perspective, we classified our determinants into two overarching categories: organisational intrinsic value support (containing co-mentor 
consultation, supervisory support for volitional mentoring and learning opportunities) and hindrance demands (containing time pressure and organisational restructuring). This classification has much appeal, as the theoretical underpinnings differ for determinants across categories but overlap for those within categories. For example, supervisory support forms an integral part of autonomy-supportive work climates characteristic of intrinsic value support, whereas restructuring fits theoretical notions of job insecurity pertinent to hindrance demands. It furthermore contains across-discipline precursors of autonomous motivation, citizenship behaviour (Gagné and Deci, 2005) and KS (Witherspoon et al., 2013), showing predictive validity. Hypotheses relating both categories to general willingness to mentor are detailed below.

\section{Organisational intrinsic value support}

Organisational intrinsic value support encompasses three organisational conditions: comentor consultation, supervisory support for (volitional) mentoring and learning opportunities. Co-mentor consultation refers to the opportunities mentors have to consult co-mentors for help when needed. Organisations can adopt an HR policy aimed at solidary horizontal workplace relationships through teamwork or an open-door culture. As such a policy advocates cooperation and interdependence, it enables employees to experience affiliation. Supervisory support for volitional mentoring denotes a work climate in which supervisors support their subordinates' willingness to self-initiate mentoring. Organisations can either employ autonomy-supportive supervisors or train employees with leadership qualities in this skill, thereby enabling organisational members to experience empowerment. Learning opportunities signify the means for job incumbents to invest in self-development. Organisations can pursue an HR policy directed at continuous learning through on-the-job experimenting, access to training courses and task rotation. As such a policy espouses a development philosophy characterised by optimal challenge, it enables employees to experience personal growth.

All these HR policies are signals that employers desire a caring professional relationship with their employees. In this situation, intrinsic value support instils feelings of loyalty in organisational members through basic human need fulfilment. This logic is consistent with the notion of the "new" psychological contract (Pruijt, 2013): employers invest in employees' well-being and development in exchange for solidarity. This solidarity can manifest itself in a higher motivation to engage willingly in pro-organisational activities. Mentoring can be seen as an activity through which employees express their goodwill, as transferring job-related knowledge to junior staff members likely contributes to the successorship of enterprisespecific knowledge. Hence, mentoring represents the prototype of optimal worker functioning that follows from employees' perceptions of their employers' investments in a work environment supportive of intrinsic values and the capacity of the latter to fulfil employees' basic human needs. Therefore, we hypothesise:

H1. Employees who experience opportunities for co-mentor consultation are more likely to mentor others.

H2. Employees who experience supervisory support for their self-initiation are more likely to mentor others.

H3. Employees who experience organisationally-arranged learning opportunities are more likely to mentor others.

\section{Hindrance demands}

Hindrance demands comprise two workplace characteristics: time pressure and organisational restructuring. Time pressure entails employees' perceived (in)ability to fulfil their formal job duties on time. As a workplace characteristic that renders mentoring unrewarding and energy-consuming (Allen et al., 1997a; Billett, 2003), time pressure 
hinders employees from feeling efficacious in their daily work surroundings, thereby frustrating their need for competence. Relatedly, as external job pressures rob employees of their sense of volition, time pressure likely also thwarts employees' need for autonomy. According to SDT, both processes of need frustration prevent employees from functioning optimally. This reasoning leads to the prediction that time pressure dampens employees' motivation to informally mentor junior colleagues, as mentoring is a form of optimal worker functioning. Accordingly, we propose:

H4. Employees who experience time pressure are less likely to mentor others.

A similar frustration may arise when employees' jobs are in jeopardy because of perceptions of organisational restructuring with forced lay-offs. Employees who are aware of their employers' efforts to flatten the management structure might be less inclined to volitionally assume the mentoring role because of their tempered feelings of organisational bonding. Theoretically, during reorganisations with compulsory redundancies, employees may no longer feel part of a collective entity that equally promotes the interests of all. Forced downsizings may further nurture employees' feelings of work incompetence, as employees' fear that their job security is at stake might detract them from the work itself. That is, restructuring frustrates employees' need for relatedness and competence, as it signals a self-centred culture with only a few survivors. According to SDT, this need frustration prevents employees from exhibiting pro-organisational behaviour akin to general willingness to mentor. Accordingly, we predict:

H5. Employees who have recently experienced or are experiencing an organisational restructuring are less likely to mentor others.

Figure 1 depicts our theoretical framework.

Figure 1 Proposed theoretical framework

Perceived organisational intrinsic value support

Co-mentor's mentoring support

Supervisor's support for selfinitiation

Learning opportunities

\section{Hindrance demands}

Time pressure

Organisational restructuring
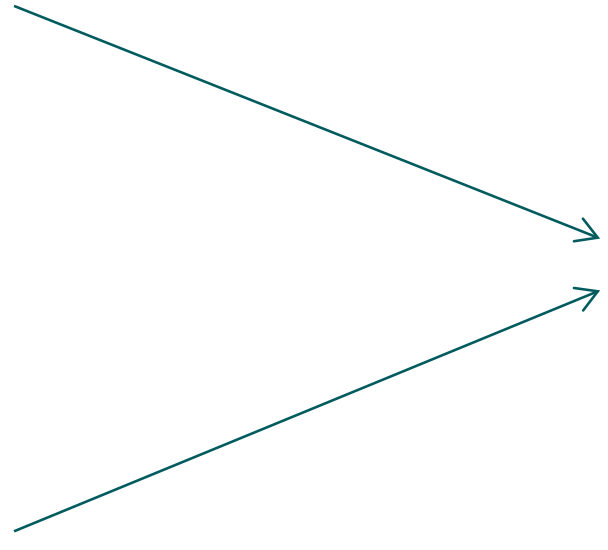


\section{Method \\ Procedure and participants}

We conducted a vignette study to test our hypotheses. Before collecting the data, we performed a pilot study and consulted a bilingual speaker to check the Dutch translations of the English questionnaire items. In all, 57 respondents took part in our pilot study, which exceeds the minimum threshold of 30 for a valid assessment of the internal consistency of latent constructs (Yurdugül, 2008). A screening of our pilot sample revealed that respondents were predominantly male (54\%) with an average age of 49 years old. Almost $41 \%$ held an occupation in which knowledge preservation is important for sustainable organisational growth. Examples include IT/R\&D/engineering (12\%) and health care (18\%).

Only employed persons with an occupational tenure of more than 10 years participated in our pilot study and completed the final questionnaire. This selection criterion was based on the career stage theory of Super (Aryee et al., 1994). According to this theory, respondents with an occupational tenure of more than 10 years fit the maintenance stage, a period in one's professional career in which employees can be considered experts in their occupational field and may be willing to mentor junior staff.

Although career stage theories have sometimes been criticised for their reduced utility in predicting mentoring intentions (Allen, 2003), we adhere to Super's theory for three reasons. First, in almost all instances, the mentor is defined as a senior employee with abundant experience and extensive (job-related) knowledge. As we focus on career-related mentoring, occupational expertise is a valuable asset of potential mentors. Second, whilst most studies on ageing in the workplace use calendar age as a proxy for career and life stage processes (Froehlich et al., 2015), age and career stage may not be as intimately intertwined as in previous eras. This means that employees of the same age may not be equipped with the same expert knowledge and, therefore, may not have the same occupational tenure. Finally, we included both managerial and non-managerial employees in our sample. The rationale behind this choice is that efforts to prune managerial jobs (CBS, 2018) may have led to an increased demand for non-managerial employees willing to mentor junior staff.

\section{Survey and sample}

After the pilot study, we made some slight amendments to the initial questionnaire - such as the rewording of items accompanying the latent constructs - and invited 2,247 respondents who fit the target group to complete the final questionnaire. The respondents were part of the PanelClix online panel. We prefer PanelClix to other agencies for two reasons. First, PanelClix owns the largest active panel in the Netherlands, is ISO-26326 certified and meets the rules of conduct specified by ESOMAR, the global representative of market research agencies. To ensure the quality, representativeness and integrity of its panel, PanelClix imposes high-quality standards upon its panel by continuously monitoring for active membership and any fraudulent behaviour. Second, PanelClix has much affinity with research in the IT sector, which epitomises the Dutch knowledge-intensive industry.

We explained the study's objectives to respondents before their completing the questionnaire and ensured confidentiality of information and anonymity of responses. Respondents could supply an email address if they were interested in receiving the outcomes of the study. Although we regarded this opportunity as an excellent means to boost the response rate, it may have led to a small yet uncontrollable bias because it may have particularly allured individuals whose career was at stake to participate. Respondents who successfully completed the survey received an incentive ranging from $€ 0.98$ to $€ 1.30$, depending on the time spent. Although this reward may have made respondents feel appreciated, we do not consider it high enough to have induced individuals to take part. 
The survey was open for eight weeks (October-November 2017). To boost the response rate, reminders were sent after six weeks. A total of 998 respondents completed the questionnaire. Of them, 845 provided reliable and usable information (a response rate of $38 \%$ ). Although lower than average for questionnaires administered to individuals, this rate is still within the accepted range (Baruch and Holtom, 2008). Data from these 845 respondents were stored in a secured computer system and linked to the large-scale labour market research - "ArbeidsmarktGedragsOnderzoek" - of Intelligence Group, a Dutch data and tech agency specialising in recruitment, employability and labour market communication.

We screened the data and found the average occupational tenure was 23 years $(S D=8.2)$ and the average organisational tenure was 18 years $(S D=10.3)$. Respondents were on average 49 years old $(S D=8.6)$, predominantly male $(58 \%)$, non-managerial $(68 \%)$ and with medium (39\%) or higher (46\%) education levels. Half of them held an occupation in which the successorship of craftsmen knowledge is important for sustainable organisational growth. Examples include IT/R\&D/engineering (15\%), health care (15\%), education (9\%) and finance (5\%).

Although our sample was heterogeneous in nature, it was not representative of the Dutch labour force; however, that heterogeneity was preferable because we aimed to assess the influence of organisational conditions on mentoring intentions rather than to draw conclusions about the share of Dutch employees willing to mentor junior staff.

\section{Dependent variable: mentoring intentions}

Respondents read a short introductory text detailing the nature and form of mentoring studied. Drawing upon Allen (2003) and Allen et al. (1997a), we described mentoring as "a volitional activity that transcends formal job requirements and is undertaken for the purpose of sharing job-related knowledge with the protégé and assisting the latter in achieving career advancement" (informal career support). After the introductory text, each respondent was randomly assigned three vignettes and asked to what extent they would be willing to become a mentor based on the work situation listed and also with a protégé as imagined. Scale anchors ranged from 0 (very unlikely) to 10 (very likely) to assume the mentoring role. We also asked respondents to assess how well the hypothetical work situation in each vignette represented a real-life work scenario, using an 11-point scale, ranging from 0 (very unrealistic) to 10 (very realistic).

\section{Independent variables: vignette conditions}

We defined five vignette conditions ( $a$ " 1 " indicating that the condition was present and a "O" indicating it was absent). We derived operationalisations from well-established measures of value support, POS or demands, attesting to the construct validity of the conditions studied. The first condition was co-mentor support, which assessed whether employees had the opportunity to consult co-mentors for help (parallel item short version POS survey: "help is available from the organization when I have a problem"; Eisenberger et al., 1986, p. 502). The second condition was supervisory support for self-initiation, which measured whether supervisors supported employees' volitional "intended" decisions to invest additional time in mentoring (parallel condition autonomy-supportive work climate (SDT): "supervisors' encouragement of self-initiation"; Gagné and Deci, 2005, p. 355). Our third condition, learning opportunities, assessed the means for self-development opportunities (parallel item Aspiration Index (SDT): "organisational importance of [...] investments in self-development"; Van den Broeck et al., 2014, p. 1909). Fourth, we discerned time pressure. This condition assessed whether employees were able to fulfil their primary job duties on time. We worded this condition based on mentors' statements highlighting the time commitments they faced in their work (Allen et al., 1997a; Billett, 2003; 
Ragins and Scandura, 1999). The final condition was organisational restructuring, which measured whether the organisation went through a reorganisation with compulsory redundancies during the preceding year. We worded this condition based on the operationalisation of restructuring used in the Dutch Study on Transitions in Employment, Ability and Motivation (Van den Heuvel et al., 2014), which followed the stem "Did the company you work for carry out a reorganisation (with compulsory redundancies) in the past 12 months?"

As each condition was dichotomous in nature, we discerned a total of $32(2 \times 2 \times 2 \times 2 \times$ 2) unique combinations of vignette conditions. In fact, with the inclusion of two control conditions (each assessed with a dichotomous variable), 128 unique combinations were possible. Contrary to factorial experiments (Rossi and Nock, 1982), respondents need not judge all combinations, which is why each received a sample of vignettes. All levels of the same vignette condition (the "ones" and "zeros") had the same likelihood of being included in the sample.

\section{Control variables: the individual level}

Employee characteristics previously found to affect the outcome (mentoring intent) were included as potential confounders. First, and following Allen (2003), we adjusted for age (years), occupational tenure (years) and hierarchical plateauing (four items; e.g. "The likelihood that I will get ahead in my organization is limited"; $\alpha=0.86$ ). Second, and drawing upon Allen et al. (1997b) and Allen (2003), we controlled for experience as a protégé ("In my worklife, I have had [some number of] mentor(s)"; recoded into a dummy variable of $0=$ no mentor or $1=$ one or more) and experience as a mentor. We assessed the latter variable with the question "During your career, has there been an individual who you have taken a personal interest in; who you have guided, sponsored, or otherwise had a positive and significant influence on their professional career development? In other words, have you ever been a mentor?" Anchors were $0=$ no and $1=$ yes. Third, and drawing upon Allen et al. (1997b) and Allen (2003, 2007), we focussed on other-oriented empathy (four items; e.g. "When I see someone being taken advantage of, I feel kind of protective toward them"; $\alpha=0.66$ ), locus of control (four items; e.g. "When I get what I want, it's usually because I worked hard for it"; $\alpha=0.68$ ) and helpfulness (four items; e.g. "I have done volunteer work for a charity"; $\alpha=0.68$ ). Finally, and relying upon Allen et al. (1997b) and Allen (2003), we concentrated on developmental proactivity (five items; e.g. "I think about how I can keep doing a good job in the future"; $\alpha=0.76)$, gender ( $0=$ male; $1=$ female), educational attainment $(1=($ not $)$ finished primary school through $6=$ master $/ \mathrm{PhD}$; normally distributed) and leadership position $(0=$ no; $1=$ yes $)$ as demographic and labour market controls. Except for helpfulness, which was assessed with response categories ranging from 1 (never) to 5 (very often), all composite measures were scored using Likert-type response formats ranging from 1 (strongly disagree) to 5 (strongly agree). Scale scores represent the mean of the items. Multicollinearity was absent in any instance.

To prevent respondent fatigue, we used shortened versions of well-established scales to measure the five latent constructs (hierarchical plateauing, other-oriented empathy, locus of control, helpfulness and developmental proactivity). We selected items based on factor loadings as well as content validity. To validate factor structure, we performed a confirmatory factor analysis using the Satorra-Bentler scaled $\chi^{2}$ test statistic and robust standard errors. To examine discriminant validity, we compared the hypothesised five-factor model with two three-factor models and a one-factor model. As expected, the five-factor model provided the best fit to the data, with all alternative models showing a significant deterioration in model fit in comparison. Results are available upon request. 


\section{Control conditions: the vignette level}

To mask our experimental (vignette) conditions, we included two control conditions in our vignettes: protégé willingness to learn and protégé-mentor similarity. Both aspects appeared to affect a mentor's decision to enter into a mentorship with a particular protégé (Allen et al., 1997a). We operationalised protégé willingness to learn with a dichotomous variable: $1=$ willing to learn and $0=$ unwilling to learn. Likewise, we measured protégé-mentor similarity as $1=$ the protégé reminds the mentor of himself or herself early in his or her career and $0=$ this is not the case. We randomly varied the order of the vignette and control conditions across the vignettes to avoid a situation in which the order might affect the outcome. Table 1 provides a description of our vignette and control conditions. Appendix 1 shows an example of a vignette.

\section{Analytical strategy}

As vignettes were clustered within employees, we performed a multilevel analysis. First, a null model was specified in which we estimated errors at both the vignette and the employee levels. This two-level model leads to the intra-class correlation as a measure for the dependence of errors, which enabled us to include predictors at both the vignette and the employee levels without inflating the Type I error rate. Second, we entered the individual-level control variables into the equation (Model 1a). Continuous control variables were grand mean centred to facilitate parameter interpretation and to address collinearity. Next, we included the control conditions (Model 1b), followed by the vignette conditions in a final step (Model 2). We used the difference in the $-2 \times \log$ likelihood to assess model fit and relied upon the AIC to address model complexity. In addition, we calculated the $R^{2}$ as an effect size measure using the formulae provided by Hox (2010): $R l^{2}=\left(\sigma^{2} \mathrm{eb}-\sigma^{2} \mathrm{en} /\right.$ $\left.\sigma^{2} \mathrm{eb}\right)$ and $R_{2}^{2}=\left(\sigma^{2} \mu \mathrm{Ob}-\sigma^{2} \mu \mathrm{On} / \sigma^{2} \mu \mathrm{Ob}\right)$.

We ran our multilevel model twice. In the first run, we relied upon the final sample of 845 respondents ( $N=2,520$ vignettes, Table 2 ) to test our expectations. In the second run, we used a sample in which we excluded the vignettes we deemed most unrealistic. Such a run enables us to improve the credibility of the vignette conditions presented. Simpson and Piquero (2002) adopted a similar strategy to respond to the general criticism that situations in vignettes may lack realism, which might jeopardise the external validity of the results

Table 1 Conditions, their levels and their operationalisation

Control conditions

Protégé willingness to learn

Protégé-mentor similarity

Experimental conditions

Co-mentor's mentoring support

Supervisor's support for selfinitiation

Learning opportunities

Time pressure

Organisational restructuring
Protégé willing to learn Protégé not willing to learn

Protégé-mentor similarity

Protégé-mentor dissimilarity

Being able to consult co-mentors if necessary

Being unable to consult co-mentors if necessary

Supervisor's support for volitional mentoring

Absence of supervisor's support for volitional mentoring

Opportunities for self-development

No opportunities for self-development

Failure to fulfil formal job duties in time

Being able to fulfil formal job duties in time

Experienced a reorganisation with compulsory redundancies during past 12 months

Not experienced a reorganisation with compulsory redundancies during past 12 months
0 (ref)

1

0 (ref)

1

0 (ref)

1

0 (ref)

1

0 (ref)

1

0 (ref)

1

0 (ref) 
(Rossi and Anderson, 1982). In practice, we analysed respondents' assessments of whether the vignettes were realistic and excluded those with a score more than one standard deviation below the mean $(M=4.5 ; S D=2.7)$ from the analysis. The rerun $(N=$ 2,078 vignettes, not shown) revealed negligible differences in parameter estimates, indicating that the vignette results from the first run are robust against threats of external validity. Results are available upon request.

\section{Results}

\section{Multilevel results}

Table 2 displays the results from our first multilevel analysis for employees' mentoring intention. The null model showed significant variability in intentions to mentor at both the employee $\left(\sigma^{2} \mu 0=3.35, p<0.001\right)$ and the vignette level $\left(\sigma^{2} e=3.12, p<0.001\right)$. Adding Level-2 individual-level control variables in Model 1a significantly improved the model fit $\left(\chi^{2}(7)=130.48, p<0.001\right)$. Inclusion of our control conditions in Model $1 \mathrm{~b}$ further

\section{Table 2 Results from the multilevel analysis for employees' mentoring intention}

\begin{tabular}{|c|c|c|c|c|c|c|c|c|}
\hline & Mode & & Model & & Model 1 & & Model & \\
\hline Independent and control varia & les & se & $b$ & se & $b$ & se & $b$ & se \\
\hline $\begin{array}{l}\text { Fixed effects } \\
\text { Employee level }^{\mathrm{a}} \text { Level 2) }\end{array}$ & & & & & & & & \\
\hline Control variables & & & & & & & & \\
\hline Age (years) & & & 0.01 & 0.01 & $0.01^{* * * *}$ & 0.01 & $0.02^{*}$ & 0.01 \\
\hline Hierarchical plateauing & & & $-0.36^{* * *}$ & 0.09 & $-0.36^{* * *}$ & 0.09 & $-0.37^{* * *}$ & 0.08 \\
\hline Experience as a mentor $(1=y$ & & & $0.42^{* *}$ & 0.16 & $0.42^{* *}$ & 0.16 & $0.44^{* *}$ & 0.16 \\
\hline Experience as a protégé $(1=y$ & & & $0.57^{* * *}$ & 0.16 & $0.56^{* * *}$ & 0.16 & $0.53^{* *}$ & 0.15 \\
\hline Helpfulness & & & $0.23^{*}$ & 0.10 & $0.24^{* *}$ & 0.09 & $0.23^{*}$ & 0.09 \\
\hline Gender ( 1 = female) & & & -0.22 & 0.14 & $-0.24^{* * * *}$ & 0.14 & -0.20 & 0.14 \\
\hline Developmental proactivity & & & $0.66^{* * *}$ & 0.14 & $0.69 * * *$ & 0.14 & $0.68^{* * *}$ & 0.14 \\
\hline Vignette level (Level 1) & & & & & & & & \\
\hline Control conditions & & & & & & & & \\
\hline Protégé willingness to learn & & & & & $1.30^{* * *}$ & 0.07 & $1.25^{* * *}$ & 0.07 \\
\hline Protégé-mentor similarity & & & & & $0.30 * * *$ & 0.07 & $0.32^{* * *}$ & 0.07 \\
\hline Experimental conditions & & & & & & & & \\
\hline Co-mentor's mentoring suppo & & & & & & & $0.41^{* * *}$ & 0.07 \\
\hline Supervisor's support for self-ir & iation & & & & & & $0.78^{* * *}$ & 0.07 \\
\hline Learning opportunities & & & & & & & $0.40^{* * *}$ & 0.07 \\
\hline Time pressure & & & & & & & $-0.56^{* * *}$ & 0.07 \\
\hline Organisational restructuring & & & & & & & $-0.19^{* *}$ & 0.07 \\
\hline Intercept & $5.30^{* * *}$ & 0.07 & $4.76^{* * *}$ & 0.14 & $3.95^{* * *}$ & 0.15 & $3.55^{* * *}$ & 0.17 \\
\hline Variance covariance estimates & random effects) & & & & & & & \\
\hline$\sigma^{2} e$ & $3.12^{* * *}$ & & $3.12^{* * *}$ & & $2.67^{* * *}$ & & $2.34^{* * *}$ & \\
\hline$\sigma^{2} \mu 0$ & $3.35^{* * *}$ & & $2.72^{* * *}$ & & $2.71^{* * *}$ & & $2.73^{* * *}$ & \\
\hline-2 Log Likelihood (-2LL) & $11,229.19$ & 11,0 & 098.71 & 10, & 801.02 & 10,5 & 559.54 & \\
\hline$\chi^{2}$ & & & $130.48^{* * *}$ & & $297.69^{* * *}$ & & $241.48^{* * *}$ & \\
\hline df change & & & 7 & & 2 & & 5 & \\
\hline $\mathrm{AIC}$ & $11,235.19$ & 11,1 & 118.71 & $10, \varepsilon$ & 825.02 & 10, & 593.54 & \\
\hline$R^{2}$ Level 1 (vignette level) & & & - & & 0.15 & & 0.10 & \\
\hline$R^{2}$ Level 2 (employee level) & & & 0.19 & & - & & - & \\
\hline
\end{tabular}

Notes: $p($ rho $)=0.52 ;{ }^{* * * *} p<0.10 ;{ }^{*} p<0.05 ;{ }^{* *} p<0.01 ;{ }^{* * *} p<0.001 . n=845$ respondents; 2,520 vignettes (15 identical vignettes were dropped from the final analysis); aMaximum likelihood estimation is used. bVariance components covariance structure used to mimic the composite residual of Model 0-2. cNon-significant coefficients for occupational tenure, other-oriented empathy, locus of control, leadership position and educational attainment are removed for reasons of parsimony and to improve readability. 
enhanced model fit $\left(\chi^{2}(2)=297.69, p<0.001\right)$ and lowered the Level-1 variance by $15 \%$ compared with the null model. In Model 2, the vignette conditions were included in the equation, which led to a significant drop in the $-2 \times$ log likelihood, a substantially lower AIC compared with the former models and an additional reduction in the Level-1 variance of $10 \%$ (25\% compared with the null model). These indices clearly indicate that our vignette conditions as a set uniquely contributed to the prediction of mentoring intent.

H1 assumes a greater willingness to mentor junior staff among those who can consult comentors. We found a significant and positive parameter estimate for co-mentor support $(b=$ $0.41, p<0.001$ ), confirming our first hypothesis. $H 2$ predicts a greater readiness to mentor junior colleagues when supervisors support employees' volitional "intended" decisions to become mentors. Further, $\mathrm{H} 3$ posits a higher intention to pass along job-related expertise to entry-level employees among those who are able to invest in self-development. As shown in Table 2, we observed positive and significant parameter coefficients for both supervisors' support for employees' self-initiation $(b=0.78, p<0.001)$ and learning opportunities $(b=0.40$, $p<0.001$ ), supporting both $H 2$ and $H 3$. H4 states that mentoring intentions are negatively associated with time pressure, that is, a sheer lack of time in daily functioning. Table 2 shows a negative and significant coefficient for time pressure $(b=-0.56, p<0.001)$, supporting $H 4$. According to $H 5$, a negative association exists between mentoring intentions and organisational restructuring, that is, reorganisations with forced lay-offs. The corresponding, statistically significant parameter estimate was negative $(b=-0.19, p<0.01)$, corroborating $H 5$.

\section{Discussion}

This study represents one of the first efforts to understand the relationships between organisational conditions and workplace characteristics and midcareer and senior employees' willingness to mentor volitionally. Before detailing implications, we should make clear that our conclusions apply particularly to non-managerial employees. We consider this an addition to the literature for two reasons. First, we portray mentoring as a volitional activity. This opens up possibilities to concentrate especially on those who intend to mentor protégés because it is enjoyable. Such a dedicated focus is commendable, as a remaining unanswered question is how non-managerial employees' mentoring intention can be fostered. Second, half the non-managerial subsample is employed in knowledge-intensive industries such as IT/technology, pharmacy/health care or finance. Almost two thirds of them hold an occupation in which intergenerational knowledge transfer is indispensable for sustainable organisational growth, enhancing the utility of our study for the KM literature.

\section{Theoretical implications}

A first notable finding is that perceptions of co-mentor consultation, supervisory support for employees' self-initiation and learning opportunities positively predict experienced employees' willingness to volitionally mentor a junior colleague, conceptualised as an exemplary form of OCB. This finding carries three implications. First, from a mentoring perspective, it attests to the pivotal role organisational intrinsic motivators play in enabling volitional mentoring. This association extends our knowledge, as prior research has focussed overwhelmingly on the role individual (intrinsic) motivators play in eliciting mentoring intent (Allen, 2007). Second, from a KM perspective, it reinforces extant research on the role organisational aspects play in facilitating KS (Razmerita et al., 2016; Witherspoon et al., 2013) by showing that similar organisational motivators have predictive validity for general willingness to mentor, construed as a means to nurture KM. Third, from a theoretical perspective, it underlines the usefulness of a combined SDT and POS approach to understanding pro-organisational behaviour, as it attests to the role the content of organisational value support plays in instilling feelings of loyalty in employees. The same "combined" theoretical perspective was adopted by Gagné et al. (2010) and Gillet et al. (2013), who found that POS was positively linked to employees' autonomous (volitional) 
motivation (both studies) as well as to their effective organisational orientations (solely applies to Gillet et al., 2013). However, whereas Gagné et al. (2010) and Gillet et al. (2013) used SDT and POS to explain volitional worker functioning in general, we are one of the very few who relied on both theories to explain intended volitional functioning among prospective mentors in particular.

The aforementioned implications lead us to conclude that there is room to integrate SDTand POS-based research on the content of organisational value support into the KM and mentoring literature. We envisage this integration in two ways. First, we see possibilities for enriching relevant theoretical research by importing SDT-based research on the individual motivator-KS link (Razmerita et al., 2016) into research on the organisational motivator-KS link. Second, we advise researchers to develop a SDT- and POS-based mediation model in which volitional mentoring is posited to mediate the relationship between organisational motivators and KS. Extant research (Karkoulian et al., 2008; Razmerita et al., 2016; Witherspoon et al., 2013), including our study, suggests that there is merit in this recommendation.

Regarding the workplace characteristics, we find a reduced willingness to mentor among those who have recently experienced or are experiencing a reorganisation with compulsory redundancies. Applying SDT, reorganisations with forced lay-offs constitute a potential hindrance demand that distorts basic human need fulfilment on which optimal worker functioning is supposed to rest. This reasoning is consistent with the premise of the "old" psychological contract theory (Pruijt, 2013): employers invest in job security in exchange for solidarity. If job security cannot be guaranteed, then solidary employee behaviour may not occur.

In addition, our results show a lower general willingness to mentor among those who regularly fail to finish their formal job duties on time. This finding supports the premise of SDT that time pressure, as a potential hindrance demand, blocks optimal worker functioning through failure to meet employees' needs for fellowship, felt competence and self-directedness. However, assuming that mentoring is a form of employee learning, it is interesting to note that time pressure repeatedly has been found to be positively related to employee learning (Van Harten, 2016). A possible explanation for the differential effects on learning and mentoring may lie in the scope of these activities: learning can be either in-role or extra-role, while informal mentoring is explicitly extra-role. As such, informal mentoring requires an additional investment in time on top of the efforts expended to meet formal deadlines. To simultaneously fulfil both "duties", employees must exert continuous effort, which ultimately may be draining. In support of this view, Ragins and Scandura (1999) found a negative association between expected costs (e.g. energy drain) and intentions to informally mentor others.

A second explanation for the differential effects of time pressure may relate to the prime actors involved in learning. In almost all instances, the prime actor in charge of learning in the studies that report a positive linkage between time pressure and learning is the learner recipient who did not have to expend additional effort in the transfer of enterprise-specific knowledge. In our study, the prime actor in charge of learning is the mentor who did have to invest additional effort in the transfer of enterprise-specific knowledge. In this situation, time pressure may lead to a decrement in learning, because the knowledge provider may feel extremely time impoverished. This contrasts with the former situation, in which it is plausible that at least some learning might occur even in the presence of time pressures, because the learner recipient may not feel as time impoverished as the knowledge provider. On the contrary, time pressures might signal that the current work situation is suboptimal, incentivising the learner recipient to consider learning a useful strategy to combat future time pressures. Hence, time pressure can be both detrimental and beneficial for learning-induced behaviour, 
possibly because of the scope (in-role versus extra-role) of this behaviour, the energetic costs associated with it and the actor in charge of learning.

The findings gathered for our control and vignette variables yield several conclusions. First, higher mentoring intentions were reported by those who proactively learn in their present job. Likewise, a positive association was observed between previous mentoring experience (either as a mentor or as a protégé) and mentoring intent. Third, protégé willingness to learn appeared to positively predict experienced employees' willingness to mentor a junior colleague. In contrast, a lower willingness to mentor was found among those who faced hierarchical plateauing. Taken together, these results suggest that mentoring intentions are largely rational in nature: through mentoring a junior colleague, experienced employees can elicit important knowledge from learning-oriented protégés or are otherwise able to enlarge the knowledge reservoir built up either through proactive learning in everyday work practice or during previous mentorships. In addition to self-enhancement motives, altruistic motives may underlie mentoring intentions as shown by the positive coefficients for helpfulness and mentor-protégé similarity. That is, theoretical mechanisms detailed in the pro-social personality literature might have additional predictive power when assessing mentoring intent. Apparently, psychological (arguments related to intrinsic value support), instrumental and altruistic (pro-social) motives should be considered supplemental rather than standalone explanations for general willingness to mentor. Individual- and contextual-level variables of a similar nature appear also to act as key, across-discipline antecedents of KS (Nguyen et al., 2019; Witherspoon et al., 2013), strengthening the link between the KM and mentoring literature drawn earlier.

\section{Limitations and future research directions}

This study has four limitations that could be addressed in future research. First, we limited our attention to the role the organisational context plays in employees' intention to volitionally (i.e. informally) mentor junior colleagues, and it remains unclear whether the same conditions apply to formal mentorships, those in which employees are mandated to participate as part of their formal job descriptions (Eby and Lockwood, 2005). Mentors are often forcefully (i.e. involuntarily) recruited, which makes formal mentoring a form of controlled rather than autonomous motivation. Therefore, other theoretical mechanisms might underlie employees' intention to formally mentor junior colleagues. To our knowledge, no one has yet identified these mechanisms. To address this gap, future research could simultaneously investigate informal and formal mentorships. Such attempts likely also contribute to the KM literature, as most KS studies concentrate on volitional $\mathrm{KS}$ at the expense of a dedicated focus on involuntary KS and knowledge hoarding (Nguyen et al., 2019). An exciting route in this regard may be to study what organisational conditions nurture involuntary KS and whether this effect passes through formal mentoring.

A second limitation relates to our use of vignettes to measure mentoring decisions. Respondents rated their mentoring intentions based on a hypothetical description of a work situation. As such, planned rather than actual behaviour was examined. Although intentions are widely believed - and accepted - as indicative of actual behaviour (Sheeran, 2002), future research could examine the extent to which mentoring intentions translate into actual mentoring behaviour.

Third, our data were collected at one point in time, which makes it difficult to establish causality. Longitudinal research is relevant to determine unambiguously the direction of the relationships found. However, we derived our hypotheses from well-established theories such as POS (Eisenberger et al., 1986) and SDT (Gagné and Deci, 2005), which propose that organisational support predicts employee behaviour and concomitant attitudes. In addition, the set-up of our vignettes forced respondents to base their mentoring intention on the specified work situation. Hence, it is plausible that the direction of the hypothesised relations is correct. Nevertheless, future research could adopt a multiple-wave study design 
to assess the possibility of reversed causation or the effect mentorships have on their organisational contexts. Such a design may bring more nuance to the cross-sectional work of Baranik et al. (2010) and Park et al. (2016), who found that participation in mentorships predicts protégés' POS. As such, their results were in the opposite direction of our findings, namely that POS predicts mentors' participation in mentorships. In addition, research efforts could be expended in "reverse mentoring", which entails the process in which protégés support the developmental needs of mentors (Haggard et al., 2011). Beyond its form, researchers could pay attention to the way knowledge is shared in a mentorship. In today's digital world, e-mentoring, in which mentors and protégés communicate using electronic devices, gains in importance. Future research could assess whether the same organisational conditions as in this study apply to reverse and e-mentoring.

Fourth, the dichotomous answer format for organisational restructuring could be nuanced in future research. The "yes/no" answer for the condition "reorganisations with compulsory redundancies" may be too simplistic, given potential differences in respondents' perceived fairness in case their organisations are forced to prune the workforce. Notwithstanding this contention, we are confident that a "yes/no" answer format for restructuring is valid for two reasons. First, this format enables us to test the role job insecurity (versus its opposite "security") as a potential hindrance demand plays in optimal worker (e.g. mentor) functioning. Second, the dichotomous variable for restructuring is statistically significant and does not interfere with the effect of the other conditions, leading to unbiased estimates.

Figure 2 depicts our corroborated theoretical framework enriched with research avenues.

\section{Practical implications}

Before detailing implications for practice, we wish to point out that we consider volitional mentoring advantageous over formal training. This is because volitional mentoring usually sorts a multidirectional as opposed to a unidirectional learning effect associated with formal training. This contention is supported by research showing that employees who envisage volitional mentoring are more eager to disseminate and use knowledge to the benefit of their organisation (Karkoulian et al., 2008). We recommend practitioners interested in volitional mentoring to adopt the following HR policy measures.

\section{Figure 2 Corroborated theoretical framework, including research avenues}

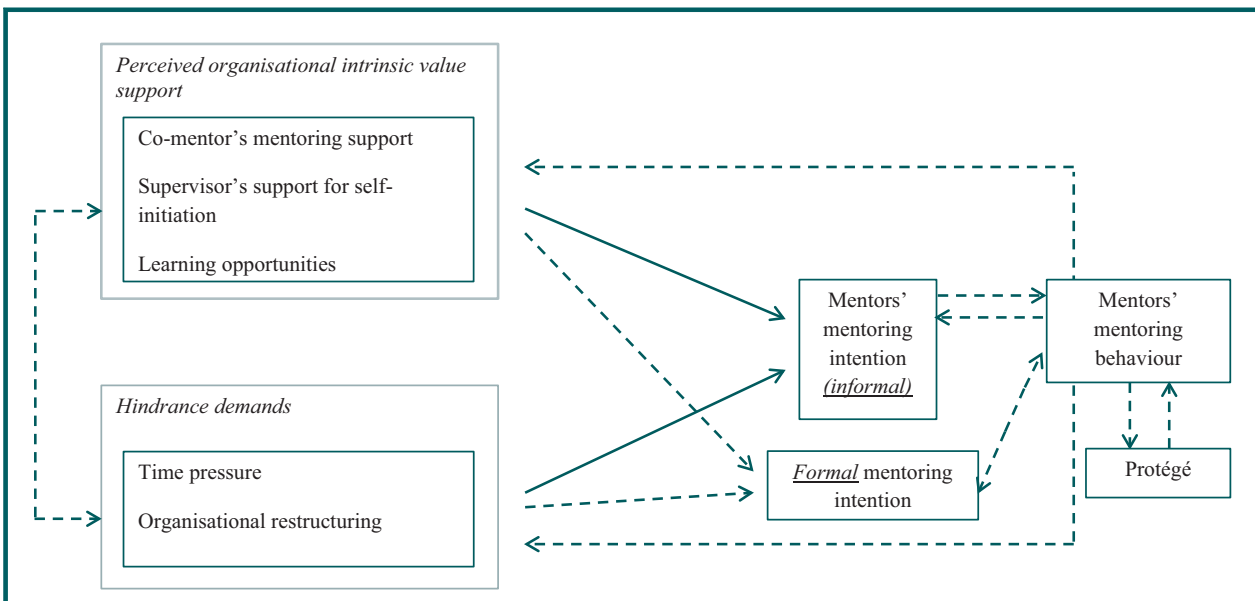

Notes: Straight lines represent the corroborated theoretical framework, dotted lines and feedback loops represent the research avenues 
First, organisations do a good job when they employ supervisors who are able to applaud their subordinates' intention to engage volitionally in activities beyond their formal duties. Supervisors could make their subordinates aware of their positive attitude towards volitional mentoring by integrating regular dialogues about citizenship activities into the annual employee evaluation cycle.

Second, organisations could benefit from adopting an open-door policy that normalises consultations amongst mentors. Such a policy could be supported with initiatives to convene periodic social meetings in which mentors can openly discuss mentoring-related problems, share best practices, offer unambiguous feedback and engage in networking. As these meetings intensify mentors' social ties and allow interdependence, they strengthen feelings of relatedness peculiar to optimal functioning (Van den Broeck et al., 2014).

Strengthening employees' feelings of relatedness should not remain limited to relationships between colleagues. As discussed earlier, employees are more eager to mentor in the absence of organisational restructuring. This highlights the importance of a solidary employer-employee relationship - one in which both members are willing to fulfil obligations laid down in the psychological contract. This does not necessarily mean, however, that employers merely offer job security in exchange for solidarity. As our finding for learning opportunities suggests, employers do a great job when they also espouse a development philosophy aimed at continuous learning. To achieve this goal, organisations could foster an "employability culture" (Nauta et al., 2009) that promotes on-the-job experimenting, stimulates personal growth and allots employees sufficient latitude for extra-role developmental activities. This recommendation is supported by an additional analysis (not shown) on a subsample of experienced employees showing that midcareer and senior employees are more eager to assume the mentoring role if their organisation espouses an employability culture. Supervisors of learning-oriented protégés could aid their organisation by encouraging their subordinates to showcase their learning motivation or by making them aware of the bi-directional nature of the mentorship. Beyond boosting mentoring intent, this supervisory style can facilitate the management of expert and novel (technical) knowledge through ensuring a mutual learning experience.

A final implication concerns the trade-off that should be made between the effort expended in learning and the time needed to fulfil formal and informal duties. As our results indicate, time pressure inhibits mentoring, which underlines the need to unburden employees. A useful practice in this regard is job carving, which means that simple, routine-intensive tasks are trimmed away and delegated to a colleague (Dekker et al., 2013). As long as it does not remove tasks that are the most valuable to employees, job carving may be an excellent way to reduce formal job pressures and, thus, to pave the way for volitional mentoring.

\section{Conclusion}

This study shows that organisations can enhance experienced employees' intention to volitionally provide career support to junior colleagues through endorsing intrinsic values (e.g. providing learning opportunities) and removing hindrance demands (e.g. lowering time pressures). We extend the KM and mentoring literature by conducting a semiexperiment on the organisational drivers and barriers of general willingness to mentor, construed as a means to nurture KM. By forcing respondents to base their mentoring intentions on a parsimonious yet theoretically sound set of organisational aspects, we respond to Witherspoon et al.'s (2013) call to study KS and concomitant attitudes from specific organisational scenarios.

\section{References}

Allen, T.D. (2003), "Mentoring others: a dispositional and motivational approach", Journal of Vocational Behavior, Vol. 62 No. 1, pp. 134-154. 
Allen, T.D. (2007), "Mentoring relationships from the perspective of the mentor", in Ragins, B.R. and Kram, K.E. (Eds), The Handbook of Mentoring at Work: Theory, Research, and Practice, Sage Publications, CA, pp. 123-147.

Allen, T.D., Eby, L.T., O'Brien, K.O. and Lentz, E. (2008), "The state of mentoring research: a qualitative review of current research methods and future research implications", Journal of Vocational Behavior, Vol. 73 No. 3, pp. 343-357.

Allen, T.D., Poteet, M.L. and Burroughs, S.M. (1997a), "The mentor's perspective: a qualitative inquiry and future research agenda", Journal of Vocational Behavior, Vol. 51 No. 1, pp. 70-89.

Allen, T.D., Poteet, M.L., Russell, J.E.A. and Dobbins, G.H. (1997b), "A field study of factors related to supervisors' willingness to mentor others”, Journal of Vocational Behavior, Vol. 50 No. 1, pp. 1-22.

Aryee, S., Chay, Y.W. and Chew, J. (1994), "An investigation of the predictors and outcomes of career commitment in three career stages", Journal of Vocational Behavior, Vol. 44 No. 1, pp. 1-16.

Baranik, L.E., Roling, E.A. and Eby, L.T. (2010), "Why does mentoring work? The role of perceived organizational support”, Journal of Vocational Behavior, Vol. 76 No. 3, pp. 366-373.

Baranik, L.E., Wright, N. and Reburn, K. (2017), "Mentoring relationships in online classes", The Internet and Higher Education, Vol. 34, pp. 65-71.

Baruch, Y. and Holtom, B.C. (2008), "Survey response rate levels and trends in organizational research", Human Relations, Vol. 61 No. 8, pp. 1139-1160.

Billett, S. (2003), "Workplace mentors: demands and benefits", Journal of Workplace Learning, Vol. 15 No. 3, pp. 105-113.

CBS (2018), "Werkzame beroepsbevolking; beroep [employed labour force; occupation]", available at: http://statline.cbs.nl/Statweb/publication/Employedlabourforce (accessed 24 May 2020).

Cropanzano, R. and Mitchell, M.S. (2005), "Social exchange theory: an interdisciplinary review", Journal of Management, Vol. 31 No. 6, pp. 874-900.

Dekker, R., Freese, C., Oonk, V. and Waasdorp, G.J. (2013), Schaarste Bestaat Niet [Scarcity Doesn't Exist], Stichting Management Studies, Koninklijke Van Gorcum BV, Assen.

Eby, L.T. and Lockwood, A. (2005), "Protégés and mentors' reactions to participating in formal mentoring programs: a qualitative investigation”, Journal of Vocational Behavior, Vol. 67 No. 3, pp. 441-458.

Eisenberger, R., Huntington, R., Hutchison, S. and Sowa, D. (1986), "Perceived organizational support", Journal of Applied Psychology, Vol. 71 No. 3, pp. 500-507.

Froehlich, D.E., Beausaert, S.A. and Segers, M.S. (2015), "Age, employability and the role of learning activities and their motivational antecedents: a conceptual model", The International Journal of Human Resource Management, Vol. 26 No. 16, pp. 2087-2101.

Gagné, M. and Deci, E.L. (2005), "Self-determination theory and work motivation", Journal of Organizational Behavior, Vol. 26 No. 4, pp. 331-362.

Gagné, M., Forest, J., Gilbert, M.-H., Aubé, C., Morin, E. and Malorni, A. (2010), "The motivation at work scale: validation evidence in two languages", Educational and Psychological Measurement, Vol. 70 No. 4, pp. 628-646.

Gallupe, B. (2001), "Knowledge management systems: surveying the landscape", International Journal of Management Reviews, Vol. 3 No. 1, pp. 61-77.

Gillet, N., Huart, I., Colombat, P. and Fouquereau, E. (2013), "Perceived organizational support, motivation, and engagement among police officers", Professional Psychology: Research and Practice, Vol. 44 No. 1, pp. 46-55.

Haggard, D.L., Dougherty, T.W., Turban, D.B. and Wilbanks, J.E. (2011), "Who is a mentor? A review of evolving definitions and implications for research", Journal of Management, Vol. 37 No. 1, pp. 280-304.

Hox, J.J. (2010), Multilevel Analysis: Techniques and Applications, 2nd ed., Routledge, New York, NY.

Janssen, S., Van Vuuren, M. and De Jong, M.D.T. (2014), "Motives to mentor: self-focused, protégéfocused, relationship-focused, organization-focused, and unfocused motives", Journal of Vocational Behavior, Vol. 85 No. 3, pp. 266-275. 
Karkoulian, S., Halawi, L.A. and McCarthy, R.V. (2008), "Knowledge management formal and informal mentoring: an empirical investigation in Lebanese banks", The Learning Organization, Vol. 15 No. 5, pp. 409-420.

Koster, F., De Grip, A. and Fouarge, D. (2011), "Does perceived support in employee development affect personnel turnover?", The International Journal of Human Resource Management, Vol. 22 No. 11, pp. 2403-2418.

Kram, K.E. (1985), Mentoring at Work: Developmental Relationships in Organizational Life, Scott, Foresman, Glenview, IL.

Nauta, A., Vianen, A., Van der Heijden, B., Van Dam, K. and Willemsen, M. (2009), “Understanding the factors that promote employability orientation: the impact of employability culture, career satisfaction, and role breadth self-efficacy", Journal of Occupational and Organizational Psychology, Vol. 82 No. 2, pp. 233-251.

Nguyen, T.M., Nham, T.P., Froese, F.J. and Malik, A. (2019), "Motivation and knowledge sharing: a metaanalysis of main and moderating effects", Journal of Knowledge Management, Vol. 23 No. 5, pp. 998-1016.

Organ, D.W. (1988), Organizational Citizenship Behaviour: The Good Soldier Syndrome, Lexington Books, Lexington, MA.

Park, J.H., Newman, A., Zhang, L., Wu, C. and Hooke, A. (2016), "Mentoring functions and turnover intention: the mediating role of perceived organizational support", The International Journal of Human Resource Management, Vol. 27 No. 11, pp. 1173-1191.

Pleijers, A. and De Winden, P. (2014), "Een leven lang leren: deelname aan opleidingen, informeel leren en ervaren resultaten [lifelong learning: training participation, informal learning and experiences]", CBS/ Sociaaleconomische Trends, Vol. 1, pp. 1-19.

Pruijt, H.D. (2013), "Employability, empowerment and employers, between debunking and appreciating action: nine cases from the ICT sector", The International Journal of Human Resource Management, Vol. 24 No. 8, pp. 1613-1628.

Ragins, B.R. and Scandura, T.A. (1999), "Burden or blessing? Expected costs and benefits of being a mentor", Journal of Organizational Behavior, Vol. 20 No. 4, pp. 493-509.

Razmerita, L., Kirchner, K. and Nielsen, P. (2016), "What factors influence knowledge sharing in organizations? A social dilemma perspective of social media communication", Journal of Knowledge Management, Vol. 20 No. 6, pp. 1-31.

Rossi, P.H. and Anderson, A.B. (1982), "An introduction", in Rossi, P.H. and Nock, S.L. (Ed.), Measuring Social Judgments: The Factorial Survey Approach, Sage Publications, Beverly Hills, pp. 15-67.

Rossi, P.H. and Nock, S.L. (Ed.) (1982), Measuring Social Judgments: The Factorial Survey Approach, Sage Publications, Beverly Hills.

Sheeran, P. (2002), "Intention-behavior relations: a conceptual and empirical review", European Review of Social Psychology, Vol. 12 No. 1, pp. 1-36.

Simpson, S.S. and Piquero, N.L. (2002), "Low self-control, organizational theory, and corporate crime", Law \& Society Review, Vol. 36 No. 3, pp. 509-547.

Van den Broeck, A., De Cuyper, N., De Witte, H. and Vansteenkiste, M. (2010), "Not all job demands are equal: differentiating job hindrances and job challenges in the Job Demands-Resources model", European Journal of Work and Organizational Psychology, Vol. 19 No. 6, pp. 735-759.

Van den Broeck, A., De Cuyper, N., Baillien, E., Vanbelle, E., Vanhercke, D. and De Witte, H. (2014), "Perception of organization's value support and perceived employability: insights from self-determination theory", The International Journal of Human Resource Management, Vol. 25 No. 13, pp. 1904-1918.

Van den Heuvel, S., Geuskens, G., Van der Meer, L., Wind, A. and Leijten, F. (2014), "Study on Transitions in Employment, Ability and Motivation (STREAM)", Technical Report TNO, Leiden.

Van Emmerik, I.J.H., Scheurs, B., De Cuyper, N., Jawahar, I.M. and Peeters, M.C.W. (2012), "The route to employability: examining resources and the mediating role of motivation", Career Development International, Vol. 17 No. 2, pp. 104-119.

Van Harten, E.J. (2016), "Employable ever after: examining the antecedents and outcomes of sustainable employability in a hospital context", Doctoral dissertation, available at: https://dspace.library.uu.nl/ handle/1874/340549 (accessed 31 October 2018). 
Wallander, L. (2009), "25 Years of factorial surveys in sociology: a review", Social Science Research, Vol. 38 No. 3, pp. 505-520.

Webster, J.R., Beehr, T.A. and Love, K. (2011), "Extending the challenge-hindrance model of occupational stress: the role of appraisal", Journal of Vocational Behavior, Vol. 79 No. 2, pp. 505-516.

Wickert, A. and Herschel, R. (2001), "Knowledge-management issues for smaller businesses", Journal of Knowledge Management, Vol. 5 No. 4, pp. 329-337.

Witherspoon, C.L., Bergner, J., Cockrell, C. and Stone, D.N. (2013), "Antecedents of organizational knowledge sharing: a meta-analysis and critique", Journal of Knowledge Management, Vol. 17 No. 2 , pp. 250-277.

Yurdugül, H. (2008), "Minimum sample size for Cronbach's coefficient alpha: a monte-carlo study", H.U. Journal of Education, Vol. 35, pp. 397-405. 


\section{Appendix 1. Example of a vignette}

Imagine: you become a mentor of a less experienced colleague, called the protégé. As a mentor, you transfer job-related knowledge to the protégé. You also suggest new ideas and assist the protégé in achieving career advancement. You volitionally assume the mentoring role beyond your formal job duties and don't get paid for your role. You do have, however, latitude over your choice of a protégé. One important goal of mentoring is that you help your organisation preserve enterprise-related knowledge accumulated over the years.

You fulfil your mentoring role in the following work context:

- You are able to consult co-mentors if necessary

- Your protégé is willing to learn

- Your supervisor supports volitional mentoring

- Your organisation offers no opportunities for self-development

- You regularly fail to fulfil formal job duties in time

- Your protégé doesn't remind you of yourself early in your career

- Your organisation carried out a reorganisation with compulsory redundancies during the past 12 months

To what extent are you willing to become a mentor, given the work context imagined?

\begin{tabular}{|l|l|l|l|l|l|l|l|l|l|l|}
\hline 0 & 1 & 2 & 3 & 4 & 5 & 6 & 7 & 8 & 9 & 10 \\
\hline
\end{tabular}

Very unlikely

Very likely

To what extent does the work context described above represent a real-life work scenario for you?

\begin{tabular}{|l|l|l|l|l|l|l|l|l|l|l|}
\hline 0 & 1 & 2 & 3 & 4 & 5 & 6 & 7 & 8 & 9 & 10 \\
\hline
\end{tabular}

Very unrealistic

Very realistic

\section{About the authors}

Conny J. J. Roobol is a PhD Candidate on the NWO TOP Project 'Sustaining Employability' at the Department of Public Administration and Sociology, Erasmus University Rotterdam. Her dissertation concentrates on the interrelationships between employability-enhancing practices (e.g. mentoring), employability and sustainable employment. Conny J. J. Roobol is the corresponding author and can be contacted at: roobol@essb.eur.nl

Ferry Koster is an Associate Professor of Labour, Organisation and Management at the Department of Public Administration and Sociology, Erasmus University Rotterdam. His research concentrates on the interaction between employers, employees and governments. He has published extensively on HR policies, social policies and organisational behaviour.

For instructions on how to order reprints of this article, please visit our website: www.emeraldgrouppublishing.com/licensing/reprints.htm

Or contact us for further details: permissions@emeraldinsight.com 